ВОРОНОВ Виктор Васильевич - доктор социологических наук, профессор; ведущий научный сотрудник Института социологии Федерального научно-исследовательского социологического центра РАН (117218, Россия, г. Москва, ул. Кржижановского, 24/35, корn. 5; voronov@isras.ru)

ВОРОНОВА Мария Викторовна - специалист по связям с общественностью Института социологии Федерального научно-исследовательского социологического центра РАН (117218, Россия, г. Москва, ул. Кржижановского, 24/35, корп. 5; tеsaтia@gmail.com)

\title{
РАЗНОУРОВНЕВОЕ ДОЛГОСРОЧНОЕ УПРАВЛЕНИЕ ПРОСТРАНСТВЕННЫМ РАЗВИТИЕМ В СТРАНАХ БАЛТИИ: ПОДХОДЫ И МОДЕЛИ
}

\begin{abstract}
Аннотация. В статье рассматриваются теоретические и прикладные аспекты долгосрочного управления пространственным развитием стран Балтии (Латвия, Литва, Эстония) на трех уровнях управления: национальном, региональном и местном в рамках интеграционных процессов развития и административнотерриториальных реформ 2009 (Литва), 2017-2019(Эстония), 2019-2021 (Латвия) годов. Авторы дают обзор теоретических и прикладных исследований по основным подходам и моделям управления стратегией пространственного развития этих стран и их оценку. Обзор показал, что стратегия управления пространственным развитием на национальном, региональном и местном уровнях требует комплексного подхода к структурным изменениям в странах Балтии. Это включает в себя укрупнение административно-территориальных единиц внутри стран; коррекцию их роли, функций и интересов; усиление инвестиционного и кадрового потенциалов для обеспечения интеграционных процессов; расширение пространства единых социокультурных кодов жизни и поведения полиэтнических групп населения обследуемых стран и др.

Результаты исследования показывают, что существует значимый коммуникационный разрыв властных элит вертикального и горизонтального уровней управления в странах Балтии. Устранение коммуникационного разрыва возможно посредством сильной публичной организации промежуточного уровня для управления сбалансированным пространственным развитием социума. Необходимо активное взаимодействие публичной власти на всех трех уровнях управления - национальном, региональном и местном в интересах единой цели: содействия равномерному и долгосрочному развитию всего территориального пространства стран Балтии. Каждый житель этих стран должен иметь одинаковые возможности и доступные услуги независимо от места, где он живет.
\end{abstract}

Ключевые слова: страны Балтии, уровни публичного управления, пространственное развитие, экономика и политика развития, местное самоуправление

\section{Введение}

Исследование затрагивает достижение целей устойчивого развития на национальном, региональном, местном уровнях странами Балтии - членами ЕС к 2030 г. Комплекс из 17 целей, разработанных ООН для стран мира в 2015 г., включает различные социально-экономические параметры - от искоренения бедности населения и устойчивого будущего городов, населенных пунктов до формирования общей позиции и общей стратегии в интересах такого развития ${ }^{1}$. Такая возможность для стран Балтии имеет две основы: политическую и экономическую. Политическая - необходимость активного продвижения взаимодействия публичной власти на трех уровнях управления - национальном, региональном и местном в интересах единой цели: содействия равномер-

117 целей устойчивого развития - пособие по преображению окружающего мира. Доступ: https://news.myseldon.com/ru/news/index/235038818 (проверено 17.11.2021). 
ному и долгосрочному развитию территории. Экономическая - преобладающее наличие высоких расходных обязательств при низкой бюджетной обеспеченности местных самоуправлений для развития, особенно малых городов и сельских поселений. Пока что в этом плане неплохо себя чувствуют лишь жители агломераций этих стран.

Механизм исполнительной координации стратегии территориально-пространственного развития стран Балтии должен учитывать две группы факторов: внешние (действия и интересы ЕС) и внутренние (национальные, региональные и местные интересы в своих странах). Страны Балтии демонстрируют различные подходы к стратегии пространственного управления своим развитием в составе ЕС: Латвия и Литва - преимущественно децентрализованный, Эстония - выборочно децентрализованный [Rollis 2021: 121-190].

Подход политики преимущественно децентрализованной координации управления. Представители центральной политической и управленческой элиты Латвии и Литвы хорошо консолидированы, особенно представители бизнеса, которые составляют $1 / 3$ этой элиты, и принимают активное участие в работе законодательных и исполнительных органов власти ЕС в таких областях, как сельское хозяйство, энергетика, защита окружающей среды, бюджетная политика. Последнее связано с тем, что структурные фонды ЕС - социальный $(E S F)$, регионального развития $(E R D F)$, развития сельских районов $(E L F L A)$, сельскохозяйственный гарантийный фонд $(E L G F)$, морской и рыбный фонд $(\mathrm{EJZF})$ - одни из важных инструментов развития местного самоуправления и достижения их жителями 75-процентного уровня доходов от среднего по ЕС [Воронов, Ружа 2020: 439-448]. В Латвии, как и в Литве, самоуправление выполняет много функций. Чем крупнее и мощнее уровень самоуправления, тем лучше живется местному населению.

Подход политики выборочной децентрализованной координации. Правительство Эстонии пытается построить свой конструктивный и прагматичный образ в EC: много не говорящий, но при необходимости представляющий хорошо продуманные и подготовленные позиции и предложения. Децентрализация государственного управления в стране позволяет отраслевым министерствам иметь свои постоянные представительства в ЕС, которые имеют полномочия вести переговоры от имени своих министерств. Эстония активно участвует в работе законодательных и исполнительных органов ЕС по созданию общего электронного рынка ЕС, энергетике, защите окружающей среды, бюджетной политике.

\section{Две модели вертикального управления стратегией сбалансированного пространственного развития стран Балтии}

Исследователи выявили две основные модели отношений между центральной властью и местным самоуправлением, определяющие специфику культурно-исторического развития стран - членов ЕС, формирования национального государства и социокультурную характеристику местных сообществ и политических элит государства, как центральных, так и местных [Грибанова, Соотла, Керстен 2020: 35]. В западных и северных странах (Дания, Норвегия, Швеция и некоторые другие) сложилась дуалистическая модель относительно независимых сфер отношений между центральными и местными органами власти (модель баланса сил между центральным правительством и местными сообществами: выбор налогообложения местными властями и др.). Для центральных и восточноевропейских стран (Германия, страны Балтии и некоторые др.) больше характерна фузионная модель отношений между центральными и местными органами власти (модель взаимодействия, предоставляющая мест- 
ным властным элитам прямой доступ к институтам и политике центрального правительства).

Центральная власть в странах Балтии стала концентрировать в своих руках развитие регионального и местного потенциала из-за ограниченных инвестиционных ресурсов. Местные властные элиты не смогли создать достаточно сильную организацию промежуточного уровня, выступающую в роли интегрирующего центра регионального развития, объединяющего и координирующего усилия различных по своей природе активных субъектов, акторов (представителей исполнительных и законодательных органов власти, малого и среднего бизнеса, представителей гражданского общества), которая могла бы обеспечить баланс сил между центром и местным самоуправлением, выступать равноправным партнером на переговорах с центральным правительством.

Местные власти предпочитают проявлять лояльность центру, а не консолидировать между собой управление местными интересами. Поэтому не следует ожидать успеха большой перестройки институтов, которая способствовала бы инновациям. Негативный аспект централизации власти в процессах управления сбалансированным территориально-пространственным развитием заключается в том, что она создает опасения в отношении перспектив и доступности разнообразных и качественных услуг для местных жителей.

Поэтому теория и практика государственного управления предлагают эффективное решение: сформировать сильную публичную организацию промежуточного уровня (краевого - в Латвии, уездного- в Литве и Эстонии). Краевой уровень жилых территорий в Латвии представляют 36 краев (novadi) и 7 городов республиканского значения. Уездный уровень в Литве представляют 10 уездов, которые разделены на 60 самоуправлений, состоящих из 546 старостатов. Уездный уровень в Эстонии представляют 15 уездов, которые разделены на 226 самоуправлений (33 городских и 193 волостных).

Промежуточный уровень - связующее звено между муниципалитетами малых и средних городов и центральным правительством, обеспечивающий, с одной стороны, реализацию государственной политики на местном уровне, с другой - учет местных интересов при разработке общегосударственной политики. Он может оградить местные власти от излишнего давления центра и ведомственных интересов отдельных министерств. Реализация такого решения может повысить как уровень фискальной самостоятельности, так и уровень вертикального влияния МСУ. Сейчас по этим позициям страны Балтии показывают пока слабый потенциал: индекс фискальной автономии (самостоятельности) в Латвии равен 16 из 100 единиц, в Литве и Эстонии - по 32; индекс вертикального влияния МСУ в Литве и Эстонии равен 33 из 100 единиц, лишь в Латвии заметно выше - 67 [Self-rule Index... 2016: 67].

\section{Бюджеты местных самоуправлений, их роль в системе}

\section{территориально-пространственного развития в странах Балтии}

Для стран Балтии характерно, что финансы всех органов местного самоуправления (по доходам) составляют одну треть (29\%-31\%) бюджета центрального правительства [Olina 2021]. В рамках имеющихся ресурсов органы местного самоуправления обеспечивают и развивают: местную инфраструктуру, доступ к медицинскому обслуживанию, образование от дошкольного до общего среднего, а также доступность других услуг (социальный транспорт, обслуживание на дому и т.д.). Муниципальные доходы обычно могут состоять из нескольких категорий: доходы от индивидуальных налогов; государственные субсидии на выполнение определенных делегированных функций; собственные доходы органов местного самоуправления за оказанные платные услуги. Основным 
источником доходов местного бюджета являются категориальные и общие дотации. Рассматривая подробную структуру доходов в Латвии и соседних странах Балтии, а также ситуацию в среднем по ЕС, можно отметить различия в структуре доходов за 2019 г. по данным Евростата 1 . В них преобладают разные основные источники доходов (см. табл. 1). В Латвии доходы самоуправления зависит преимущественно от полученных налоговых платежей: большей части общих доходов подоходного налога с населения (НДФЛ) и налога на недвижимость (3,9\% ВВП). Также значительную часть доходов составляют полученные выплаты (трансферты) из государственного бюджета для обеспечения возможности реализации делегированных государством функций, в основном в сфере образования и транспорта (3,3\% ВВП Латвии; 7,8\% ВВП Литвы; 6,4\% ВВП Эстонии), а также выплаты, полученные местным самоуправлением из фонда выравнивания финансов самоуправления Латвии, выплаты по линии проектов различных структурных фондов ЕС (0,3\% ВВП Латвии; 0,5\% ВВП Эстонии). Меньшую часть составляют доходы от платных услуг, сборов, аренды имущества и т.д., которые предоставляют местные органы власти (0,6\% ВВП Латвии; 0,4\% ВВП Литвы; 0,6\% ВВП Эстонии).

Таблица 1

\section{Структура доходов местного самоуправления в 2019 г., \% ВВП}

\begin{tabular}{|l|c|c|c|c|}
\hline \multicolumn{1}{|c|}{ Виды доходов } & ЕС- 27 & Латвия & Литва & Эстония \\
\hline $\begin{array}{l}\text { Налог на прибыль, налог на } \\
\text { имущество, НДФЛ и др. }\end{array}$ & 2,0 & 3,9 & - & - \\
\hline Выручка от сборов, платных услуг & 1,5 & 0,6 & 0,4 & 0,6 \\
\hline $\begin{array}{l}\text { Полученные текущие переводы } \\
\text { (трансферы) }\end{array}$ & 4,1 & 3,3 & 7,8 & 6,4 \\
\hline $\begin{array}{l}\text { Полученные капитальные } \\
\text { переводы (трансферы) }\end{array}$ & 0,7 & 0,3 & - & 0,5 \\
\hline Другие доходы & 0,4 & - & 0,1 & 0,1 \\
\hline Итого & 8,7 & 8,1 & 8,3 & 7,6 \\
\hline
\end{tabular}

Источник: Евростат.

Текущие расходы местных органов власти в странах Балтии составляют 22-24\% государственных расходов, однако поступления от местных налогов компенсируют при этом менее $1 \%$ затрат. Расходы также могут финансироваться за счет заемных ресурсов (реализация инфраструктурных инвестиционных проектов). Разбивка расходов по экономическим категориям и секторам показывает, что в странах Балтии большая часть ресурсов местного самоуправления тратится на образование (4,1\% ВВП Латвии; 3,0\% ВВП Литвы; 3,8\% ВВП Эстонии) (см. табл. 2 и 3). Общие государственные расходы на образование в странах Балтии также превышают средний показатель по ЕС (1,6\% ВВП). Еще одна область, в которой расходы местных органов власти отличаются от других стран ЕС, это целевое финансирование управления землей и жильем. В эту категорию входят расходы на управление природными территориями и их благоустройство (парки, детские площадки и т.д.), на содержание жилого и нежилого фонда, принадлежащего самоуправлению, на уличное освещение, инвестиции в повышение энергоэффективности городской среды.

1 https://ec.europa.eu/eurostat/web/lfs/data/database (проверено 07.09.2021). 
Таблица 2

\section{Структура расходов местного самоуправления по экономическим категориям} в 2019 г., \% ВВП

\begin{tabular}{|l|c|c|c|c|}
\hline $\begin{array}{c}\text { Виды расходов по экономическим } \\
\text { категориям }\end{array}$ & ЕС- 27 & Латвия & Литва & Эстония \\
\hline Промежуточное потребление & 2,3 & 2,6 & 1,4 & 2,7 \\
\hline Вознаграждение & 3,5 & 4,4 & 5,6 & 3,1 \\
\hline Расходы на выплаты процентов & 0,2 & 0,1 & - & 0,2 \\
\hline Субсидии & 0,3 & - & - & 0,3 \\
\hline Социальные выплаты и льготы & 1,5 & 0,4 & 1,3 & 0,5 \\
\hline $\begin{array}{l}\text { Формирование основного } \\
\text { капитала или инвестиции }\end{array}$ & 1,6 & 0,7 & 0,4 & 1,3 \\
\hline Прочие расходы & 1,2 & 1,3 & 0,2 & 0,5 \\
\hline Итого & 10,6 & 9,5 & 8,9 & 8,6 \\
\hline
\end{tabular}

Источник: Евростат.

Другая ситуация наблюдается в расходах на здравоохранение, где уровень расходов местного самоуправления в Латвии $(1,0 \%$ ВВП) ниже, чем в Литве $(1,5 \%)$, Эстонии $(1,4 \%)$ и в среднем по ЕС $(1,7 \%$ ВВП). Расходы на общие государственные услуги в странах Балтии $(0,5-0,7 \%$ ВВП) намного ниже, чем в среднем по ЕС (1,7\% ВВП).

Поступления от НДФЛ в 2021 г. будут ниже, чем 2020 г., из-за изменения доли доходов от НДФЛ местных муниципалитетов и государства с существующей пропорции 80\% : 20\% (до 2021 г.) до 75\% : 25\% (с 2021 г.). В результате изменений бюджет местного самоуправления составит на 90 млн евро меньше, чем в 2020 г. В 2021 г. бюджет малообеспеченных муниципалитетов может быть пополнен специальным грантом государства. Для компенсации снижения доходов местного самоуправления снижено условие софинансирования бюджетов местных самоуправлений с 25\% до 15\% общей стоимости проекта, а для инвестиционных проектов в образовательных учреждениях оно установлено еще ниже - $10 \%$.

Таблица 3

Расходы местного самоуправления по секторам в 2019 г., \% ВВП

\begin{tabular}{|l|c|c|c|c|}
\hline \multicolumn{1}{|c|}{ Виды расходов по секторам } & $\mathbf{E C - 2 7}$ & Латвия & Литва & Эстония \\
\hline Общие государственные услуги & 1,7 & 0,7 & 0,5 & 0,7 \\
\hline $\begin{array}{l}\text { Общественный порядок и } \\
\text { безопасность }\end{array}$ & 0,3 & 0,2 & 0,1 & - \\
\hline $\begin{array}{l}\text { Экономическая деятельность, в } \\
\text { т.ч. транспорт }\end{array}$ & 1,4 & 1,3 & 0,8 & 1,4 \\
\hline Защита окружающей среды & 0,6 & 0,2 & 0,3 & 0,3 \\
\hline $\begin{array}{l}\text { Управление земельными } \\
\text { участками и жильем }\end{array}$ & 0,4 & 1,1 & 0,4 & 0,3 \\
\hline Здоровье & 1,7 & 1,0 & 1,5 & 1,4 \\
\hline Отдых, культура, религия & 0,6 & 1,0 & 0,5 & 0,9 \\
\hline Образование & 1,6 & 4,1 & 3,0 & 3,8 \\
\hline Социальная защита & 2,4 & 1,1 & 0,9 & 0,7 \\
\hline Итого & 10,7 & 10,7 & 8,0 & 9,5 \\
\hline
\end{tabular}

Источник: Евростат. 
Несмотря на эти меры, ожидается рост долга местных органов власти, который до сих пор составлял около $6 \%$ ВВП. В этой связи заслуживает внимания опыт Эстонии по улучшению качества местной жизни. Там местному самоуправлению разрешили иметь минимальный индикативный порог на уровне 0,5 млн евро собственных инвестиционных средств в год и минимальное число жителей в 6-7 тыс. чел., чтобы участвовать в достаточно крупных инвестиционных проектах, которые финансируются программами и структурными фондами ЕС.

\section{Выводы}

1. Опыт стран Балтии позволяет утверждать, что масштабные реформы управления реализуются на основе определенных подходов и моделей, которые регулируют этот процесс. Подходы уровней управления могут продвигать эффективные изменения на всех уровнях исполнительной власти и в состоянии реализовать единое видение стратегии пространственного развития и приоритетов на национальном, региональном и местном уровнях, расширение пространства единых социокультурных кодов жизни и поведения полиэтнических групп населения и др.

2. Очевидна необходимость достижения региональными и местными уровнями управления устойчивого инвестиционного потенциала, сбалансированного пространственного развития за счет расширения источников финансирования на базе как бюджетно-налоговых преференций центральной власти, так и увеличения перспектив доступа к программам и структурным фондам ЕС. Этому может способствовать и фузионная модель отношений между центральными и местными органами власти.

3. Опыт проведения административных реформ в странах Балтии в 2009, 2017-2019, 2019-2021 гг. показал необходимость сильной публичной организации промежуточного уровня управления сбалансированным пространственным развитием локальных территорий. Промежуточный уровень (краевой - в Латвии, уездный - в Литве и Эстонии) может служить действенным связующим звеном между муниципалитетами и центральным правительством, обеспечивая, с одной стороны, реализацию государственной политики на местном уровне, с другой - учет местных интересов при разработке общегосударственной политики.

\section{Список литературы}

Воронов В.В., Ружа О.П. 2020. Опыт Латвии в развитии малых городов: возможности и барьеры. - Пространственное развитие малых городов: социальные стратегии и практики: коллективная монография (отв. ред. М.Ф. Черныш, В.В. Маркин; предисл. М.К. Горшкова). М.: Изд-во ФНИСЦ РАН. С. 422-448.

Грибанова Г.И., Соотла Г., Керстен К. 2020. Реформы местного самоуправления в Эстонии: институциональный контекст, намерения и результаты. Балтийский регион. Т. 12. № 1. С. 32-52.

Oliņa L. 2021. Pašvaldību finanses pārmaiņu priekšā un to izaicinājumi. Rīga: Latvijas Banka. 14 lpp.

Self-rule Index for Local Authorities (Release 1.0): final report. European Commission. Luxembourg: Publications Office of the European Union. 2016. 89 p.

Rollis I. 2021. Izpildvaras politikas koordinācijas mehānismu eiropeizācija: Igaunijas, Latvijas un Slovēnijas pieredze. Promocijas darbs. Rīga: Latvijas Universitāte. 292 lpp. 
VORONOV Victor Vasil'evich, Dr.Sci. (Soc.), Professor; Leading Researcher at the Institute of Sociology - Branch of the Federal Center of Theoretical and Applied Sociology, Russian Academy of Sciences (bld. 5, 24/35 Krzhizhanovskogo St, Moscow, Russia, 117218; voronov@isras.ru)

VORONOVA Maria Viktorovna, Public Relations Specialist at the Institute of Sociology - Branch of the Federal Center of Theoretical and Applied Sociology, Russian Academy of Sciences (bld. 5, 24/35 Krzhizhanovskogo St, Moscow, Russia, 117218; tesamia@gmail.com)

\title{
MULTI-LEVEL LONG-TERM SPATIAL DEVELOPMENT MANAGEMENT IN THE BALTIC STATES: APPROACHES AND MODELS
}

\begin{abstract}
The article considers theoretical and applied aspects of long-term management of spatial development of the Baltic States (Latvia, Lithuania, Estonia) at three levels of management: national, regional and local within the framework of integration processes of the development and administrative-territorial reforms in 2009 (Lithuania), 2017-2019 (Estonia), 2019-2021 (Latvia). The authors give a review of theoretical and applied research on the main approaches and models of managing the spatial development strategy of these countries and their assessment. The review shows that the spatial development management strategy at the national, regional and local levels requires an integrated approach to structural changes in the Baltic States. This includes consolidation of administrative-territorial units within countries; correction of their roles, functions and interests; strengthening of investment and human resources to ensure integration processes; expansion of the space of common socio-cultural codes of life and behavior of multi-ethnic groups of the surveyed countries, and more. Research results show that there is a significant communication gap between the power elites of the vertical and horizontal levels of government in the Baltic States. The elimination of the communication gap is possible through a strong public organization of an intermediate level to manage the balanced spatial development of society. There is a need for active interaction of public authorities at all three levels of government: national, regional and local, in the interests of a single goal: to promote the uniform and long-term development of the entire territorial space of the Baltic States. Every resident of these countries should have the same opportunities and affordable services regardless of where he lives.
\end{abstract}

Keywords: Baltic States, levels of public administration, spatial development, economy and development policy, local governments 